\title{
GASTRIC CANGER IN NEPAL A LOCALLY ADVANCED DISEASE
}

\author{
Koirala R, Acharya N, Khanal S, Rajbhandary A
}

Deparment of General Surgery, Nepal Medical College Teaching Hospital, Attarkhel, Gokarneshwor-8,

\author{
Kathmandu, Nepal
}

\begin{abstract}
The goal of this study is to describe the distribution of gastric cancer by age, gender, duration of symptoms, nutritional status and staging of the disease based on operative findings and correlation between the data. This was an observational study. The study was conducted at Department of Surgery, Nepal Medical College Teaching Hospital from December 2012 to December 2017. All patients who were admitted to the department with a diagnosis of stomach cancer and underwent palliative or curative intent procedure were reviewed and analyzed. Out of the 80 patients, 51(63.7\%) were male and $29(36.3 \%)$ patients were female. The disease was commonest in the 6th and 7th decades of life. Majority of the patients were of Tibetoburmese (Mongolian) origin with 44 (55\%). Majority of patients, 60 (75\%) patients had long duration of illness of more than 6 months. Most of the patients had albumin level less than $3 \mathrm{gm} / \mathrm{dl}$. Gastric carcinoma is a male predominant malignancy usually of old age and commonly observed in the Tibeto-Burman group of people. Overwhelming majority diagnosed at an advanced stage and had poor prognosis.
\end{abstract}

\section{KEYWORDS}

Advanced gastric cancer, D2 dissection, Nepal

\section{CORRESPONDING AUTHOR}

Dr. Rabin Koirala,

Associate Professor,

Department of General Surgery,

Nepal Medical College Teaching Hospital

Attarkhel, Gokarneshwor-8, Kathmandu, Nepal

Email: rabinkoirala@hotmail.com

ORCID ID: 0000-0003-3912-9787 


\section{INTRODUCTION}

Gastric cancer remains the fourth most common type of cancer and is the second leading cause of cancer-related death worldwide. ${ }^{1}$ The incidence of stomach cancer is increasing in Nepal and it is one of the commonest cancers in the Nepalese population. Dried, smoked, salted foods and alcohol are considered as higher risk factors for gastric cancer in Nepal. There is a growth of stomach cancer in Nepal in certain populations, more commonly afflicted are the lower socioeconomic classes due to increase in incidence of Helicobacter pylori bacteria in these group of people. ${ }^{2}$

Due to the difficult landscapes, lower literacy rate and difficult access to health centers, people with stomach cancer usually have advanced disease at presentation. The incidence rate in men is double that of women and incidence increases with age. ${ }^{3,4}$ Even within the same geographic region certain ethnic groups have significantly higher risk of disease. ${ }^{3}$ According to the present data from Nepal, it is the $5^{\text {th }}$ commonest cancer including both genders, 3rd in males and 6th in females. ${ }^{4}$ Endoscopic biopsy is widely regarded as the most sensitive and specific diagnostic tool for gastric cancer. ${ }^{5}$ Currently, the only potentially curative treatment for gastric cancer is surgery with adequate lymph node dissection.

\section{MATERIALS AND METHODS}

Study was conducted at Department of Surgery, Nepal Medical College Teaching Hospital from December 2012 to December 2017. All patients who were admitted to the department with a diagnosis of stomach cancer and underwent palliative or curative intent procedure were reviewed and analyzed. The goal of this study was to describe the distribution of cancer by age, gender, duration of symptoms, nutritional status and staging of the disease based on preoperative investigations, operative findings and correlation between the data.

Patient's data was prospectively kept. The parameters analyzed were age, gender, location, gross and microscopic types. Cases excluded from the study were (a) Tumors with extensive areas of necrosis and no viable or normal looking tissues (b) Cases where the site of biopsy is unclear, not mentioned by endoscopist or could not be identified histologically (c) Other types of gastric malignancies (e.g., lymphoma, gastrointestinal stromal tumor etc). The data collected was analyzed using recent SPSS $16^{\text {th }}$ version.

\section{RESULTS}

In our study, 80 patients were included. Out of the 80 patients, 51(63.7\%) were male and 29 (36.3\%) patients were female. The age ranged from 30 to 80 years, more among the 6th and 7th decades of life. Majority of the patients were of Tibetoburmese (Mongolian) origin with 44 (55\%) patients out of 80 cases. Others were Caucasians in $16(20 \%)$ cases, $12(15 \%)$ were Newars, $8(10 \%)$ were of ethnic Terai origin (Fig. 1). Once careful history and examination was done, hematological, biopsy and imaging studies were sent. Hemoglobin ranges from 7.5 to $14 \mathrm{mg} / \mathrm{dl}$.

Out of 80 patients, 60 (75\%) patients had long duration of illness with duration of symptoms more than 6 months. 14 (17.5\%) patients had symptoms for 3 to 6 months and only 6 (7.5\%) patients presented early with less than 3 months of symptoms. The albumin level ranged from 2 to 4.1. Most of the patients had albumin level less than 3gm/dl suggesting poor nutritional status of the patient and long duration of disease (Table 1).

\section{Table 1: Albumin level}

\begin{tabular}{lc|} 
Albumin range & Frequency \\
$\leq 3 \mathrm{gm} / \mathrm{dl}$ & $51(63.7 \%)$ \\
$>3 \mathrm{gm} / \mathrm{dl}$ & $29(36.2 \%)$ \\
Total & 80 \\
\hline
\end{tabular}

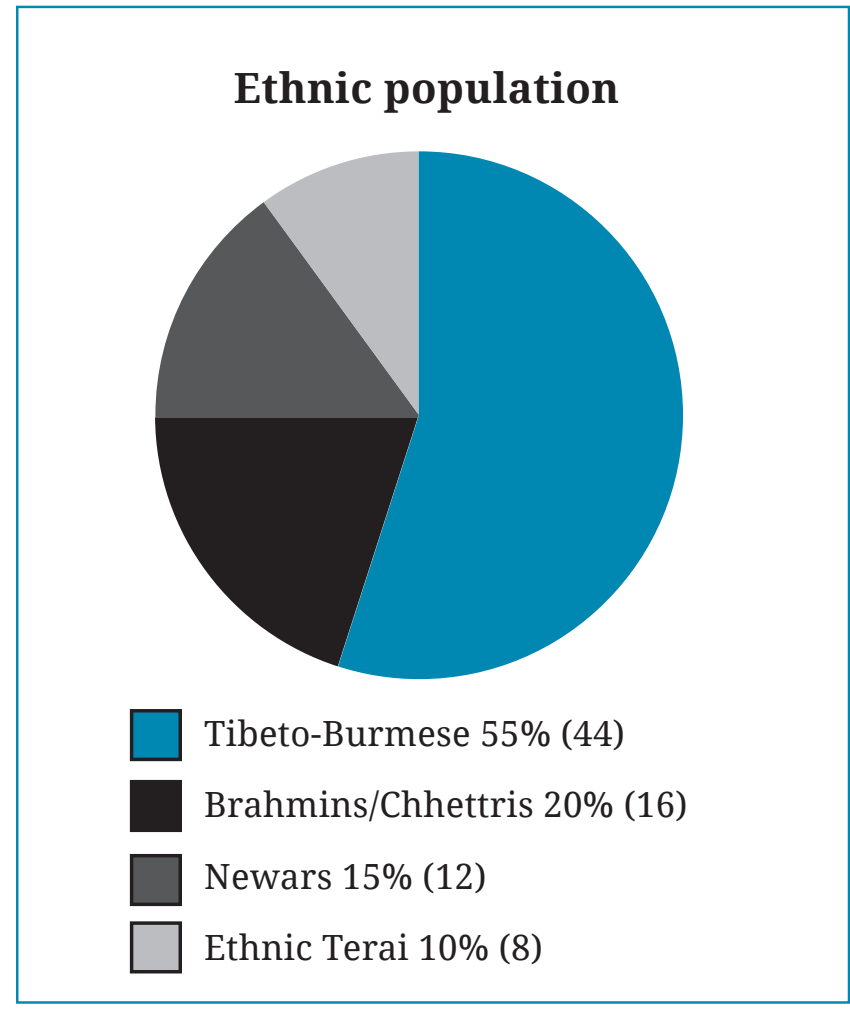

Fig. 1: Ethnic distribution 
Forty six of the patients presented with advanced metastatic or unresectable disease where as 32 patients had locally advanced disease and only 2 patients had early disease (Table 4 ). The distribution of the different stages of disease amongst male and female is shown in fig. 3.

\begin{tabular}{|lc|}
\hline \multicolumn{2}{|c|}{ Table 2: Stage of cancer } \\
\hline Stage of cancer & Frequency \\
Early cancer & $2(2.5 \%)$ \\
Locally advanced cancer & $32(40 \%)$ \\
Unresectable metastatic cancer & $46(57.5 \%)$ \\
\hline
\end{tabular}

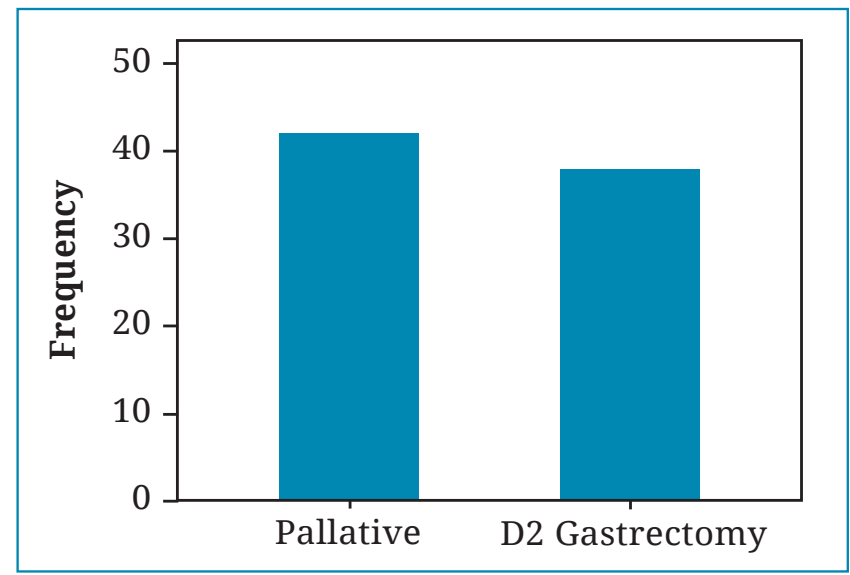

Fig. 2: Type of surgery

Curative intent surgery included D2 gastrectomy (radical resection of the stomach along with adequate lymph node dissection) which was done in $38(47.5 \%)$ cases. Most of the patients (42 or 52.5\%) underwent palliative gastrectomy, gastrojejunostomy or a feeding jejunostomy. In all the cases histopathological specimen were sent (Fig. 2).

Elderly male patients presented with advanced disease as compared to female and younger patients but it wasnt statistically significant. There was significant morbidity in a total of sixteen patients, wound infection was the most common complication followed by urinary tract infection and pneumonia. Radiology guided drainage procedure was required in two patients. Three patients underwent a redolaparotomy (3.8\%) one was for postoperative hemorrhage and the other two were for a duodenal blowout. See table 3 . There were 3 mortalities (3.8\%). One was a patient who underwent a palliative gastrojejunostomy but subsequently developed burst abdomen and pneumonia. The other two were for D2 gastrectomies. One was for a duodenal blowout and died of sepsis and its complications. The third was for postoperative bleed, on relaparotomy clots and collection were present in the lesser sac but no definitive bleeder.
Surgery remains the mainstay of curative treatment of resectable gastric cancer and complete resection of a gastric tumor with resection of adjacent lymph node is the only chance for a cure. ${ }^{16,17}$ As majority of the patients presented with advanced disease, we were unable to perform definitive surgery in them; only palliation was done.

In conclusion, gastric carcinoma is a male

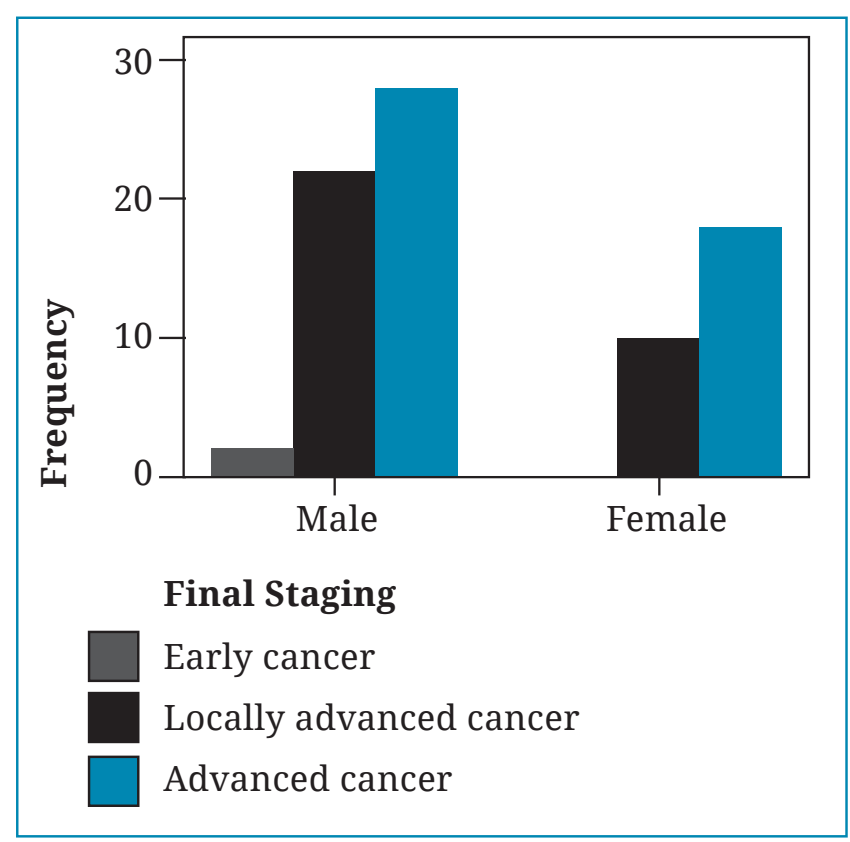

Fig. 3: Distribution of the different stages of disease amongst male and female

\begin{tabular}{|lc|}
\hline \multicolumn{2}{|c|}{ Table 3: Morbidity } \\
\hline Morbidity & $\mathbf{n}$ \\
Superficial wound infection & 13 \\
Pneumonia & 9 \\
Urinary tract infection & 8 \\
Burst abdomen & 5 \\
Intrabdominal abcess/ collection & 4 \\
\hline
\end{tabular}

\section{DISCUSSION}

Cancer health disparities are differences in the incidence, prevalence, mortality and burden of cancer and related adverse health conditions that exist among specific population groups.

Such disparities related to race and ethnicities are well described and are major public health concerns. Cancer incidence and death rates vary considerably among selected racial and ethnic groups. ${ }^{6-8}$ For example it was more prevalent in ethnic Mongolian race in our study. Prevalence of metastatic deposits and late presentation of the disease was also highest in the same population 
Table 4: Distribution of different stages of disease in various age groups

\begin{tabular}{|lcccc|}
\multicolumn{5}{c}{ Table 4: Distribution of different stages of disease in various age groups } \\
Age range & Early cancer & $\begin{array}{c}\text { Final Stage } \\
\text { Locally advanced } \\
\text { cancer }\end{array}$ & Advanced cancer & P value \\
<=40 years & 0 & 4 & 0 & \\
$\mathbf{4 0 - 5 0}$ years & 0 & 4 & 6 & \\
$\mathbf{5 0 - 6 0}$ years & 0 & 6 & 20 & 0.106 \\
$\mathbf{6 0 - 7 0}$ years & 2 & 14 & 16 & \\
$>$ 70 years & 0 & 4 & 4 & \\
\hline
\end{tabular}

group. Such disparities are seen even in the western studies. For example in a study conducted by Merchant SJ et al disparities in gastric cancer shows clear disparities between hispanics, asian and white communities in descending order. ${ }^{6}$ Ethnicity and race also had effects in overall survival. In study done by Kim et al in $2010,{ }^{7}$ on Gastric cancer among white, black, Hispanic and Asian population, Asians had highest overall survival. Asian race independently predicted improved survival for surgical patients. ${ }^{8}$

Among different studies conducted in Nepal fifty percent of patients belonged to Brahmin and Chhetris (Hill) followed by Janajatis (Hill) $35 \%$ and Newars $11 \%$, both of whom belonged to the Janajatis and amongst them it was more frequently observed in the Gurung and Sherpa community. ${ }^{9,10}$

The incidence of gastric cancer is known to increase with age with the peak incidence occurring at $60-80$ years. ${ }^{11}$ In a study done in Nepal more than half of the patients (55.7\%) were in age group of 50-70 years with the mean age of 59.6 years and male to female ratio of $2: 1 .^{12}$ Similar finding was observed in other study which showed $80.5 \%$ patients of more than 45 years and male to female ratio was $1.97: 1{ }^{13}$ Our study also showed similar results with $72.5 \%$ patients more than 50 patients and male to female ratio of 1.7:1.

Most patients were from rural areas. Most patients belong to the hilly region which makes health care access difficult and practice of traditional medicine also limits their accessibility to health care facilities. ${ }^{14}$ As their beliefs on witchcraft and reliance on traditional faith healer for treatment is quite strong among all the ethnic communities, visit to a health facility becomes inevitable only when problem gets worse or unbearable, ${ }^{15}$ delaying diagnosis and cause for late presentation. So, poverty, difficult access and belief in traditional medicine all contribute to late present. ${ }^{14,15}$ predominant malignancy usually of old age and commonly observed in the Tibeto-Burman group of people. It is usually diagnosed at an advanced stage and has poor prognosis. Thus, early detection is the key to improve the survival of gastric cancer patient.

\section{REFERENCES}

1. Jemal A, Bray F, Center MM, Ferlay J, Ward E, Forman D. Global cancer statistics. CA Cancer $J$ Clin 2011; 61: 69-90. [PubMed]

2. Poudel KK, Haung Z, Neupane PR. Trend of cancer incidence in Nepal from 2003 to 2012. Asian Pac J Cancer Prev 2016; 17: 2171-5.

3. Ferlay J, Steliarova-Foucher E, Lortet-Tieulent J, Rosso S, Coebergh JW, Comber $\mathrm{H}$ et al. Cancer incidence and mortality patterns in Europe: Estimates for 40 countries in 2012. Eur J Cancer 2013; 49: 1374-403.

4. Ferlay J, Shin HR, Bray F, Forman D, Mathers C, Parkin DM. Estimates of worldwide burden of cancer in 2008: GLOBOCAN 2008. Int'l J Cancer 2010; 127: 2893-917. [PubMed]

5. Ferlay J, Shin HR, Bray F, Forman D, Mathers C, Parkin DM. GLOBOCAN 2008, Cancer Incidence and Mortality Worldwide: IARC Cancer Base No. 10. Lyon, France: International Agency for Research on Cancer; 2010.

6. Fenoglio-Preiser C, Carneiro F, Correa P, Guilford P, Lambert R, Megraud F et al. Gastric Carcinoma. In: Hamilton SR, Aaltonen LA, eds. Pathology \& Genetics Tumors of digestive system, Lyon: IARC Press; 2000, pp 39-52.

7. Merchant SJ, Li L, Kim J. Racial and ethnic disparities in gastric cancer outcomes: More important than surgical technique? World J Gastroenterol 2014; 20: 11546-51.

8. Kim J, Sun CL, Mailey B, Prendergast C, Artinyan A, Bhatia S, Pigazzi A, Ellenhorn JD. Race and ethnicity correlate with survival in patients with gastric adenocarcinoma. Ann Oncol 2010; 21: 15260.

9. Ghosh A, Sathian B, Gharti DM, Narasimhan R, Talwar OP. Epidemiologic analysis of gastric 
carcinoma in the western region of nepal. Nepal $J$ Epidemiol 2010; 1: 27-32.

10. Ghimire B, Singh YP, Timalsina S. Post operative diagnosis of early gastric cancer in a low risk population and the possibility of risk stratified screening. Kathmandu Univ Med J 2014; 45: 32-7.

11. Nagini S. Carcinoma of the stomach: A review of epidemiology, pathogenesis, molecular genetics and chemoprevention. World J Gastrointest Oncol 2012; 4, 156-69.

12. Sah JK, Singh YP, Ghimire B. Presentation and Outcomes of Gastric Cancer at a University Teaching Hospital in Nepal. Asian Pac J Cancer Prev 2015; 16: 5385-8.

13. Khan D, Hassan MK, Rehman A et al. Gastric carcinoma: location, morphological and histological profile. J Postgrad Med Inst 2012; 26: 170-5.
14. Raut B, Khanal DP. Present status of traditional healthcare system in Nepal. Int'l J Res Ayur Pharm 2011; 2: 876-82.

15. Subba NR. Health seeking behavior of Rajbanshi community in Katahari and Baijanathpur of Morang district Nepal. JNHRC 2004; 2: 14-8.

16. Alatise O, Lawal OO, Adesunkanmi AK et al. Clinical pattern and management of gastric cancer in IleIfe, Nigeria. Arab J Gastroenterol 2007; 8: 123-6.

17. Bakari AA, Ibrahim AG, Gali BM, Dogo D, Nggada HA. Pattern of gastric cancer in north-eastern Nigeria: a clinicopathological study. J Chinese Clin Med 2010; 51: 211-5. 